\section{Consultants' involvement in the contracting process in Yorkshire region}

\author{
D C Bensley, A R Bull, R A Haward
}

Regional Department of Public Health Medicine, Yorkshire Health,

Harrogate HG1 5AH

D C Bensley, FSS, regional statistician

A R Bull, MFCM, consultant in public health medicine

R A Haward, FFCM, director of public health

Correspondence and requests for reprints to: Dr Haward.

BMf 1991;303:95

Clinicians need to be fully involved in the contracting process if service agreements between purchaser and provider are to be both accepted and workable. We performed a random sample survey of consultants in Yorkshire during February 1991 to assess their involvement in discussions about contracts.

\section{Subjects, methods, and results}

A stratified random sample design with variable sampling fraction was used to select from the 1118 consultants employed in the region. Stratification was by both district and four broad specialty groups. A total of 162 questionnaires were sent; a reminder was sent after one week and a telephone reminder given after two weeks.

Of the 162 consultants surveyed, 153 (94\%) responded. In all, $89(57 \%, 95 \%$ confidence interval 51 to $65 \%$ ) had been involved in discussing specifications for their services more than once (table), with a range across districts of $33 \%$ to $80 \%$.

In discussions about quality standards 88 (58\%, 57 to $62 \%$ ) of consultants had been involved more than once (range across districts $38 \%$ to $100 \%$ ), but $49(32 \%$ ) had not been involved at all. Significantly more respondents who were heads of department or division had been involved more than once ( 26 out of $40(65 \%)$ compared with 64 out of $112(57 \%)$ others; $\mathrm{p}<0.05)$. When asked whether their hospital or district had organised at least one event or seminar to discuss the contracting process $96(63 \%)$ consultants said no

Involvement of consultants $(n=153)$ in discussions concerning various aspects of contracts. Figures are numbers (percentages) of consultants

\begin{tabular}{lccrrr}
\hline & $\begin{array}{c}\text { On a formal/regular } \\
\text { basis }\end{array}$ & $\begin{array}{c}\text { On an informal/irregular } \\
\text { basis }\end{array}$ & Once only & Not at all & Not known \\
\hline Specification of services & $43(28)$ & $44(29)$ & $22(14)$ & $42(27)$ & $2(1)$ \\
Quality standards & $45(29)$ & $43(28)$ & $13(8)$ & $49(32)$ & $3(2)$ \\
Overall hospital services & $19(12)$ & $37(24)$ & $14(9)$ & $80(52)$ & $3(2)$ \\
Monitoring contracts & $11(7)$ & $22(14)$ & $8(5)$ & $108(71)$ & $4(3)$ \\
\hline
\end{tabular}

(range across districts $17 \%$ to $85 \%$ ). Thirty seven (24\%) consultants had attended such an event. In all, 24 consultants $(16 \%, 14$ to $18 \%)$ were members of contracting teams (range across districts $0 \%$ to $40 \%$ ); $10(25 \%)$ senior consultants were represented on these teams compared with seven $(6 \%)$ other consultants $(\mathrm{p}=0.003)$.

Discussions on the overall range of services provided by the hospital had involved 56 (37\%, 34 to $42 \%$ ) consultants more than once. Heads of department or division were more frequently involved, with 20 $(50 \%)$ consulted more than once $(\mathrm{p}<0.05)$. Only 33 consultants $(22 \%, 20$ to $26 \%$ ) had been involved more than once in discussions on how to monitor contracts. Of these, significantly more were heads of department or division (16 (41\%) compared with 26 $(23 \%)$ who were not; $p=0.03)$. These observations applied to all specialty groups. Whether or not consultants worked in units designated as NHS trusts made no significant difference.

\section{Comment}

Over a half of surveyed consultants had been involved in discussions about service specification or standards of care on more than one occasion (table), and in some districts the proportion was over $80 \%$. Given that contracting is an important new process within the NHS, this is probably satisfactory. Of concern, however, are the results showing that less than a third had been involved on a formal or regular basis, and similarly that a third had no involvement in discussions on quality issues. The variation in proportion of consultants who were aware of seminars on contracting across districts suggests that communication about such events was often inadequate.

Although $57 \%$ of consultants had been involved more than once in discussions of quality in contracts, more than two thirds had had no discussion as to how contracts are to be monitored and managed. This may reflect less overall discussion of monitoring of contracts.

We conclude that the involvement of clinicians in the contracting process, although appreciable, must increase if contracting is to develop effectively. There should be improved communication about the contracting process and more clinical involvement in consideration of how contracts should be monitored.

(Accepted 25 April 1991)
Correspondence to: Dr Williams.

\section{Raised proinsulin concentration as early indicator of $\beta$ cell dysfunction}

\author{
D R Rhys Williams, Christopher Byrne, \\ Penelope M S Clark, Lorna Cox, \\ Nicholas E Day, Gerry Rayman, Tim Wang, \\ C Nicholas Hales
}

The contributions of insulin deficiency and resistance to insulin in non-insulin dependent diabetes and impaired glucose tolerance are unresolved. Immunoradiometric assays can now distinguish proinsulin and the split proinsulins from each other and from insulin.' Patients with newly diagnosed diabetes have lower insulin concentrations 30 minutes after a $75 \mathrm{~g}$ glucose load than controls, and proinsulin-like molecules constitute a higher proportion of molecules containing insulin in these patients when fasted than in controls. ${ }^{2}$
We studied people with previously undiagnosed impaired glucose tolerance to see if they showed similar insulin and proinsulin profiles after a challenge with oral glucose.

\section{Subjects, methods, and results}

We selected subjects aged 50-64 from the age-sex register of a general practice. We excluded those known to have diabetes and those receiving long term drug treatment. We carried out a standard $75 \mathrm{~g}$ oral glucose tolerance test in 58 subjects, taking venous blood samples at 0,30 , and 120 minutes. Results were assessed according to criteria of the World Health Organisation. ${ }^{3}$ Each subject with previously undiagnosed impaired glucose tolerance was matched for sex and age (to within three years) with three controls randomly selected from the screened group.

Plasma glucose concentration was measured by a standard hexokinase method. Plasma insulin, proinsulin, and 32-33 and 65-66 split proinsulin concentrations were measured by two site immunoradiometric assays. ' Concentrations of 65-66 proinsulin were mostly 